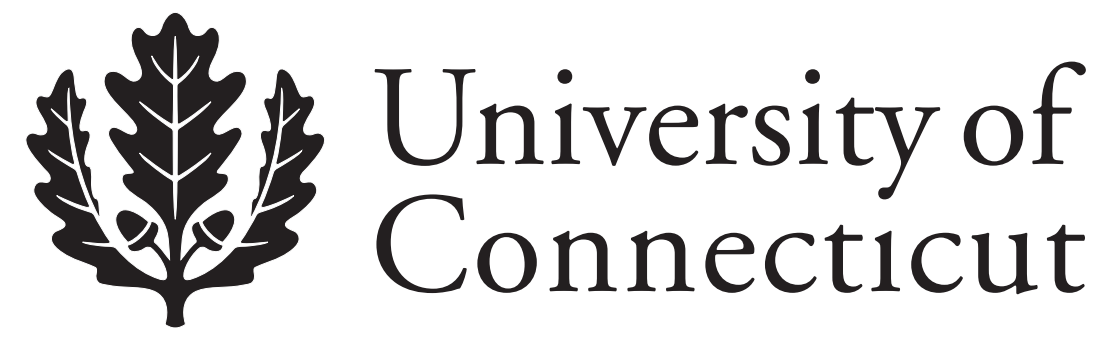

Department of Economics Working Paper Series

Markets, Contracts, and Firms: A Unified Model of Organizational Choice

Thomas J. Miceli

University of Connecticut

Working Paper 2011-08

April 2011

341 Mansfield Road, Unit 1063

Storrs, CT 06269-1063

Phone: (860) 486-3022

Fax: (860) 486-4463

http://www.econ.uconn.edu/

This working paper is indexed on RePEc, http://repec.org/ 


\begin{abstract}
This paper examines markets, firms, and the law as alternative institutional arrangements for organizing transactions that involve transaction-specific investments and uncertain performance. The analysis is the logical extension of Coase's seminal examination of the market-firm boundary on one hand, and the marketlaw boundary on the other. It thus combines insights from the literature on industrial organization and law and economics. The result is a unified framework that reveals the relative advantages and disadvantages, within a fairly simple economic setting, of market exchange, court ordering (contracts), and internal governance (agency).
\end{abstract}

Journal of Economic Literature Classification: D23, K12, L14, L22

Keywords: Asset specificity, contracts, firms, markets, transaction costs 


\section{Markets, Contracts, and Firms: A Unified Model of Organizational Choice}

\section{Introduction}

Beginning with Coase (1937), a large literature has arisen to examine the boundary between the market and the firm. ${ }^{1}$ The key question addressed by this literature is, when is it more efficient to organize a transaction through the market rather than within the confines of a firm? Such an analysis, however, often overlooks the different ways in which a market (armslength) transaction can be organized. For example, it can be a spot transaction in which the parties meet and negotiate an instantaneous exchange under certainty, or it can be governed by a contractual arrangement that was negotiated in the past before all information pertinent to the transaction was known. The advantage of the contract is that it allows commitments to be made that are enforceable by a third party (the court), thereby avoiding the holdup problem. ${ }^{2}$ (This arrangement is therefore sometimes referred to as "court ordering.") The disadvantage is that the terms of the contract must often be negotiated under uncertainty, thus leading to the possibility of costly litigation once the information is revealed.

In a sense, a contract is intermediate between a pure market transaction, where enforcement is not an issue, and a transaction within a firm, where the owner (residual claimant) can dictate the terms of the transaction. Thus, one way to think of the contract is that a court stands ready to dictate the terms of the transaction, much the way the owner of a firm could, but unlike the firm owner, the court has no financial stake in the transaction and only acts when called on. In this way, the law provides temporary access to coercion when a dispute arises in

\footnotetext{
${ }^{1}$ See, for example, Williamson (1975, 1979, 1987), Klein, Crawford and Alchian (1978), Grossman and Hart (1986), and Hart and Moore (1988, 1990). For a recent survey, see Hart (2011).

${ }^{2}$ On the holdup problem, see the references in footnote 1, as well as Goldberg (1976, 1985), Edlin and Reichelstein (1996), Segal (1999), and Bolton and Dewatripont (2005, pp. 560-578).
} 
the face of unforeseen circumstances, a kind of "temporary firm." This perspective reflects the boundary between the market (consensual exchange) and the law (court-ordered exchange), which is, of course, the general subject of Coase's other classic paper on social cost (Coase, $1960)^{3}$

By recognizing the boundary between markets and contracts on one hand, and between markets and firms one the other, the current paper therefore blends the insights from Coase's two classic papers in an effort to provide a more complete picture of the organization of exchange. The formal analysis focuses on three key factors in evaluating the choice among the various organizational forms. The first concerns the incentives for parties to make efficient transactionspecific investments prior to exchange, which has been the subject of much of Williamson's work on the advantage of firms and contracts over market exchange. The second concerns incentives for efficient performance of a transaction-that is, deciding when the transaction should be completed and when it should be breached. These two factors represent the incentive effects regarding exchange. Finally, an extension of the basic model introduces the impact of transaction or litigation costs in determining the most efficient organizational form.

\section{Of Beer and Ice: A Case Study}

To motivate the analysis, consider the well-known case of Goebel v. Linn. ${ }^{4}$ The case involved a dispute between an ice company and a brewery that arose when the ice company refused to deliver ice at the contractually set price of $\$ 2$ a ton because an unusually warm winter had caused the ice "crop" to fail. Because the brewery had a large stock of beer on hand that would have spoiled without ice, it initially agreed to a price of $\$ 3.50$ per ton and took delivery

\footnotetext{
${ }^{3}$ Also see the classic analysis of the choice between property rules and liability rules in Calabresi and Melamed (1972), which reflects the same distinction.

${ }^{4} 47$ Mich. 489, 11 N.W. 284 (1882).
} 
but later sought to have the original price reinstated by the court. The court, however, allowed the higher price to stand based on the "unexpected and extraordinary circumstances" that had arisen, ${ }^{5}$ which likely would have driven the ice company into bankruptcy had the lower price been enforced.

From an historical perspective, this case depicts a general problem faced by breweries prior to the invention of artificial refrigeration. Since the storage of beer required cool temperatures, brewers usually had to rely on caves, either natural or specially constructed for the aging of beer. The temperature of the caves was not always low enough, however, particularly during the summer months, so ice was also needed. Natural ice, cut from rivers and ponds during the winter and stored in insulated icehouses, provided the only supply. This explains why breweries initially arose in northern cities like Milwaukee, where ice was readily available during the winter. Still, the market for ice was not a dependable one since, as the Goebel case showed, mild winters often caused price spikes and supply shortages. As a result, many large breweries built their own ice houses to store ice so that it was available year round, thus removing at least some of the uncertainty over the cost of beer production (Baron, 1962, pp. 231234).

This situation presents a classic industrial organization problem in which a manufacturer needs to ensure the supply of an essential input into his production process. The asset-specificity problem arises because the manufacturer's technology requires it to initiate its production process (i.e., the brewing of beer) before the cost of the input (ice) can be known with certainty. The question is how to organize the transaction between the manufacturer and the input supplier in this setting so as to maximize the gains from trade.

\footnotetext{
${ }^{5}$ Goebel v. Linn, p. 285.
} 
One way is by a spot transaction between the manufacturer and supplier after the cost of the input is realized. The problem with this arrangement is that the input supplier may be in a position to hold up the manufacturer given that the latter has already made a non-salvageable investment that locks him into the transaction. To avoid this problem, the manufacturer could instead enter into a formal contract that specifies the price of the input before making any investments. This was what in fact happened in the Goebel v. Linn case. Although the ice company was still able to successfully hold up the brewery for a higher price, the brewery had the option of suing for breach of contract when the ice company refused to deliver at the contract price. Under the standard remedy for breach (which the brewery did not pursue), the ice company would have had to pay damages equal to the brewery's loss, thus fully compensating the brewery. ${ }^{6}$ As a final option, the manufacturer could have solved its ice supply problem by simply buying out or merging with the ice company (i.e., vertically integrating). In this way, it would have ensured the timely delivery of ice at an acceptable cost. As noted above, many large breweries pursued this option by building their own icehouses. The drawback of this arrangement, however, is the governance cost of managing the ice company, which I will model below as an agency cost.

The preceding case study shows the various options that potential traders have for organizing their transaction. All are imperfect, so the optimal choice is the one that maximizes the expected value of the transaction. The following model formally examines the factors that enter into this choice. Section 3 first examines the incentives problems (transaction-specific investment and performance), and then Section 4 explicitly introduces transaction costs.

\footnotetext{
${ }^{6}$ The brewery did not pursue the damage remedy because it is likely that it would have bankrupted the ice company (Goebel v. Linn, p. 285). The risk of bankruptcy thus shows that contracts do not completely eliminate the risk of a holdup problem (Miceli, 2002).
} 


\section{Theoretical Analysis}

Initially, I assume transaction and litigation costs are zero in order to isolate the allocative distortions inherent in the organizational forms themselves. In other words, how do the various forms affect incentives for non-salvageable, transaction-specific investments and for performance in relation to the first-best outcome? To be concrete, I couch the analysis in terms of the brewery/ice company case.

\subsection{Set-up of the Model and the Social Optimum}

Let $V(x)$ be the gross value of output produced by the brewery, given its initial investment of $x$, where $V^{\prime}>0$, and $V(x)^{\prime \prime}<0$. For example, $x$ might represent the amount of beer that it brews. Storage and sale of the beer, however, requires the timely supply of ice, the cost of which is a random variable denoted $C$, where $F(C)$ is the distribution function, and $f(C) \equiv F^{\prime}(C)>0$ is the associated density function. The sequence of decisions is crucial, since the brewery must choose $x$ before the cost of supplying ice is realized. Then, once $C$ is realized, the decision of whether or not to supply the ice is made.

As usual, the social optimum is derived in reverse sequence of time. Thus, once $C$ has been realized, it is optimal for the ice to be supplied if the cost of performance is less than the value of performance, or if $C \leq V(x)$ for any value of $x$. In contrast, if the cost of performance exceeds the value of performance-i.e., if $C>V(x)$, then the ice should not be supplied, even though this means the loss of the brewery's initial investment in beer. Given this sequence of decisions, the expression for the expected value of the brewery's investment, prior to the realization of $C$, is given by

$$
\begin{aligned}
& F(V(x)) E[V(x)-C \mid C \leq V(x)]-x \\
= & \int_{0}^{V(x)}[V(x)-C] d F(C)-x,
\end{aligned}
$$


where $F(V(x))$ is the probability of performance as a function of $x$. The brewery's optimal choice of $x$ maximizes this expression. The resulting first-order condition is given by

$$
F(V(x)) V^{\prime}(x)-1=0,
$$

which says that the brewery should invest up to the point where the expected marginal benefit equals the marginal cost. Let $x *$ denote the resulting first-best level of investment. ${ }^{7}$

The actual performance and investment decisions will be made by the relevant decisionmakers based on the organizational form governing the "transaction" between the brewer and ice supplier. The next three sections derive the equilibrium under a market transaction, a contractual arrangement, and vertical integration.

\subsection{Market Transaction}

When the brewery and ice company interact in a market setting, they engage in a spot transaction for the sale of ice once the cost of ice production is realized. I assume that they complete a transaction whenever one is jointly profitable (given $x$ and $C$ ), and then negotiate the price based on the Nash bargaining solution. A transaction is profitable whenever $V(x) \geq C$, which is the efficient condition. The resulting equilibrium price is given by

$$
P=\frac{V(x)+C}{2}
$$

Thus, the parties split the surplus from any transaction evenly. More generally, when the bargaining abilities of the parties can vary, ${ }^{8}$ the price will be given by

$$
P=\alpha V(x)+(1-\alpha) C,
$$

where $\alpha$ represents the strength of the ice company's bargaining power. The key thing to note here is that the price is increasing in $x$ for $\alpha>0$. That is, the more that the brewery has invested in reliance on the completion of a transaction with the ice company, the higher the price that the

\footnotetext{
${ }^{7}$ The second-order condition for $x *$ to be a maximum is $F V^{\prime \prime}+F^{\prime}\left(V^{\prime}\right)^{2}<0$, which I assume holds.

${ }^{8}$ See, for example, Osborne and Rubinstein (1990, p. 21).
} 
latter can extract. This represents a version of the holdup problem that can arise in spot transactions, where the parameter $\alpha$ is an index of the severity of the problem (i.e., higher $\alpha$ indicates a more severe holdup problem).

Given (4), the brewery will choose its initial investment to maximize

$$
F(V x) E[V(x)-P \mid C \leq V(x)]-x
$$

where $F(V(x))$ is the probability of performance. Substituting for $P$ from (4) yields

$$
\begin{aligned}
& F(V(x)) E[V(x)-\alpha V(x)-(1-\alpha) C \mid C \leq V(x)]-x \\
& =\int_{0}^{V(x)}[(1-\alpha)(V(x)-C)] d F(C)-x .
\end{aligned}
$$

The resulting first-order condition is

$$
F(V(x))(1-\alpha) V^{\prime}(x)-1=0
$$

Denote the solution to (6) $x_{M}$. Comparing (6) to (2) shows that $x_{M}<x *$ for $\alpha>0$. Intuitively, the brewery reduces its investment compared to the efficient level in order to lessen its vulnerability to the holdup problem. Further, $x_{M}$ is decreasing in $\alpha$, indicating that the brewery invests less as the holdup problem becomes more severe. This is the primary disadvantage of market exchange in this context.

\subsection{Long-term Contract}

As an alternative to engaging in spot transactions, the brewery and ice company can sign a long-term contract that commits the ice company to deliver ice at a pre-determined price over some prescribed time period. This avoids the need for the parties to negotiate a price for each transaction, and hence eliminates the holdup problem. Further, it creates an obligation on the part of the ice company to perform, which the brewery can enforce by legal means. Thus, in those states where the ice company chooses not to perform, the brewery can seek damages in court. (I ignore the risk of bankruptcy on the part of the input supplier in high cost states.) Let $R$ 
be the pre-determined contract price, payable on performance, ${ }^{9}$ and let $D$ be the damages in the event of breach as set by the court. (The magnitude of $D$ will be discussed below.)

The timing of events in this case is as follows. First, the brewery and the ice company sign the contract and specify the price, $R$. Then the brewery chooses $x$. Finally, the ice company realizes the cost of performance, $C$, and decides whether or not to perform. If it does not perform, the parties go to court, and the ice company is ordered to pay damages of $D$ to the brewery. ${ }^{10}$

Considering first the ice company's performance decision, once $C$ is realized, it will deliver the ice if $R-C \geq-D$, or if

$$
C \leq R+D
$$

and breach if the reverse is true. ${ }^{11}$ Recall that the condition for efficient performance, given $x$, is $C \leq V(x)$. Thus, for any $x$, the measure of damages for breach that induces the ice company to perform efficiently is $D=V(x)-R$, or, the ice company must pay the brewery its surplus from the transaction, conditional on its actual level of investment. As it happens, this measure of damages coincides with the most commonly used remedy in actual breach-of-contract cases, referred to as "expectation damages." This measure is defined to be an amount of money that leaves the promisee (in this case, the brewery) as well off as if the contract had been performed as promised (Shavell, 2004, pp. 343-344). Expectation damages induces efficient performance because it forces the ice company to internalize the full cost of breach to the brewery, given its prior investment of $x$. Note that such a measure assumes the court is able, after the fact, to

\footnotetext{
${ }^{9}$ This assumption is not essential. If the price were payable up-front (fully or partially), then the damage measure would be adjusted accordingly. See, for example, White (1988).

${ }^{10}$ Alternatively, the contract could include a stipulated damage clause, enforceable by a court, that specifies $D$ (Shavell, 2004, pp. 352-353). The conclusions would be the same in this case.

${ }^{11}$ It is possible that the parties will settle the breach suit out of court. However, the settlement amount will resemble the court-imposed remedy and hence will have a similar impact.
} 
observe and condition the amount of damages on the brewery's actual loss of income as a result of the breach, namely, $V(x)$.

Given the above damage measure, the brewery anticipates that the breach decision will be made efficiently by the ice company for any amount of $x$ that it invests. Thus, it computes its expected return from the contract to be $\mathrm{b}^{12}$

$$
F(V(x))[V(x)-R]+[1-F(V(x))] D-x .
$$

After substituting $D=V(x)-R$, this expression reduces to

$$
V(x)-R-x
$$

Thus, the brewery can proceed as if performance were certain. Consequently, its profit-

maximizing level of investment, denoted $x_{C}$, will solve the first-order condition

$$
V^{\prime}(x)-1=0
$$

which, in view of (2), results in overinvestment. This is true because the expectation damage measure provides the brewery with full insurance against breach and hence creates the usual moral hazard problem. ${ }^{13}$ Note that the result here is therefore the opposite of the outcome under market organization, which resulted in underinvestment by the brewery.

\subsection{Vertical Integration}

The third alternative to the market or contract is for brewery and ice company to vertically integrate; that is, to organize their transaction within a single firm. For concreteness, I assume that the brewery takes control of ice company, though the reverse is also possible (see,

\footnotetext{
${ }^{12}$ I don't formally examine the manner in which the price, $R$, is determined, since it is taken as fixed for purposes of all subsequent decisions. Presumably, $R$ reflects the bargaining abilities of the parties before any decisions have been made or costs realized, as opposed to the spot price above, which is negotiated after the brewery has chosen $x$ and the ice company's cost of performance has been revealed. Thus, negotiation over $R$ would not be susceptible to the holdup problem.

${ }^{13}$ If the court were able to specify a damage measure based on the efficient (as opposed to the actual) level of the brewery's investment, then it could avoid the moral hazard problem and still induce efficient performance by setting damages equal to $D=V\left(x^{*}\right)-R$. However, we assume that the informational requirements of such a measure are outside of the court's knowledge or ability to learn (Shavell, 2004, pp. 360-361).
} 
for example, Grossman and Hart, 1986). The production and delivery of ice is therefore undertaken by "employees" of the firm in return for a wage, while the "owner" (the residual claimant) decides how much to invest and when to produce. I will model this relationship as a principal-agent problem, where the brewer is the principal and the supplier of ice is the agent.

The distinguishing feature of the firm as an organizational form is that it outlives the individual transaction. To ensure this, the employees must be paid in both production and nonproduction states, though I will allow the wages to differ in those states. In particular, suppose that in the states where the (single) worker is asked to produce and "deliver" ice, he is paid $w$ (to be determined below), but when he is not asked to produce due to high costs, he is paid $w_{0}$, which is defined to be the minimum amount that prevents him from quitting (his reservation wage). In this specification, $C$ is interpreted to be the worker's realized cost of performance.

As noted, the owner chooses the maximum cost under which the firm will produce. Let $\hat{C}$ be this threshold cost level. Thus, the firm will produce when $C \leq \hat{C}$ and not produce when $C>\hat{C}$. The owner, however, is assumed not to be able to observe the realization of $C$, so he must create an incentive contract for the employee to produce only in those states where $C \leq \hat{C}$. In other words, the owner specifies a contract consisting of the wages, $w$ and $w_{0}$, and the threshold cost, $\hat{C}$, to maximize profits (the residual claim), subject to the following constraints

$$
\begin{array}{ll}
w-C \geq w_{0}, & C \leq \hat{C} \\
w-C<w_{0}, & C>\hat{C} .
\end{array}
$$

Constraint (11.1) says that the worker, after privately observing the cost of production, prefers to produce in the low cost state, ${ }^{14}$ while (11.2) says that he prefers not to produce in the high cost

\footnotetext{
${ }^{14}$ I assume that when indifferent, the worker produces.
} 
state, where $w_{0}$ is his reservation wage. Writing equation (11.1) as an equality yields the threshold cost as a function of $w$ :

$$
\hat{C}(w)=w-w_{0}
$$

Figure 1 depicts the ranges for $C$ graphically.

[Figure 1 here]

The expected profit for the owner, given (11), can be written as

$$
\int_{0}^{\hat{C}(w)}[V(x)-w] d F(C)-\int_{\hat{C}(w)}^{\infty} w_{0} d F(C)-x
$$

where the first term represents expected profits in the production state, and the second represents costs in the non-production state. The owner chooses $w$ and $x$ to maximize this expression subject to (12). Consider first the choice of $w$. The first-order condition is

$$
-F(\hat{C})+\left(V(x)-w+w_{0}\right) f(\hat{C})\left(\frac{\partial \hat{C}}{\partial w}\right)=0
$$

Since $\frac{\partial \hat{C}}{\partial w}=1$ from (12), this expression can be re-arranged to yield

$$
f(\hat{C})[V(x)-\hat{C}]=F(\hat{C})
$$

from which it follows that $V(x)>\hat{C}$. Thus, the firm underproduces, given $x$. This is true because, given the owner's inability to observe the realized cost of production, he must pay the worker a high enough wage to induce him to produce over the range where $C \leq \hat{C}$. Thus, by reducing the range of production slightly, he can pay a lower wage in the production states. At the optimum, he balances the cost of lost production against the lower expected wage bill. The resulting inefficiency represents an agency cost associated with vertical integration. In what follows, let $\widehat{w}(x)$ denote the solution to (14).

The owner's optimal investment, $x$, solves the following first-order condition

$$
\int_{0}^{\hat{C}} V^{\prime}(x) d F(C)-1-F(\hat{C})\left(\frac{\partial \widehat{w}}{\partial x}\right)+\left[V(x)-\widehat{w}(x)+w_{0}\right] f(\hat{C})\left(\frac{\partial \widehat{w}}{\partial x}\right)=0 .
$$


Since the final two terms drop out by (12) and (14), we have

$$
F(\hat{C}) V^{\prime}(x)-1=0 .
$$

Thus, the owner invests optimally, given the cost threshold $\hat{C}$.

\subsection{Comparison of the Various Forms}

The results of the preceding sections are summarized in Table 1. Note that each of the organizational forms involves some inefficiency, suggesting that no one form will be optimal in all circumstances. The spot market and long-term contract both result in efficient performance once the cost of performing is realized, but the brewery invests inefficiently under both. Specifically, it underinvests under market exchange in a strategic effort to mitigate the hold-up problem, whereas it overinvests under the long-term contract because of the moral hazard problem created by the expectation damage measure of damages from a breach by the ice company. In contrast, when the brewery and ice company merge, the integrated firm invests efficiently, but it underperforms as a result of the agency costs associated with the workers' private knowledge of the cost of performance.

\section{[Table 1 here]}

Since none of the organizational forms achieves the first-best outcome, the choice among them depends on which involves the least distortion. In the context of the current model, this will depend on the technology embodied in the brewery's gross revenue function (i.e., how important the up-front investment is), the distribution of production costs (i.e., how likely breach is), and the severity of the hold-up problem (i.e., the relative ex post bargaining strengths of the parties). Consideration of some special cases helps to illustrate the nature of the choice.

Suppose first that investment by the brewery in anticipation of performance is not important (i.e., $V$ is fixed). In that case, both the market and contract will yield the efficient 
outcome because they result in efficient performance, but the firm continues to result in underperformance because of the agency costs. Thus, when up-front investments are not important, we would the market and long-term contract to dominate vertical integration.

Alternatively, suppose that the up-front investments are important but performance is certain. In this case, the contract and firm will yield the efficient level of investment (this is true under the contract because the moral hazard problem disappears when performance is certain), whereas the market will result in too little investment because of the hold-up problem. When breach becomes possible, the costs associated with the contract and firm re-emerge and we return to the general outcome in which all forms are second-best. The only general conclusion we can draw here is that, as the likelihood of breach increases, the level of investment under the market more closely tracks the efficient level of investment as compared to the contract. This is true because the level of investment under the contract is not sensitive to the probability of breach, and thus diverges further from the efficient level as that probability increases, whereas the level of investment under the market, though inefficiently low, at least declines with the probability of breach. Consequently, as the probability of breach increases, the market and firm will tend to dominate the long-term contract, with the choice depending on the relative costs of the hold-up and agency problems.

A simple example helps to further refine these conclusions. Let $V(x)=\theta x^{1 / 3}$, and assume that $C$ is uniformly distributed on $[0,4]$. I compare the organizational forms by computing the value of expression (1) for each form while varying the production parameter $\theta$, and the bargaining power parameter $\alpha$. Table 2 shows the optimal form for each of the specifications. Note first that the market dominates for all $\theta$ when $\alpha$ is low. This is true because the brewery expects to receive a large share of the gains from ex post bargaining and thus internalizes most of 
the gains from trade. In other words, the holdup problem is not severe. (In the extreme case where $\alpha=0$, the holdup problem is absent and the outcome is first-best under market exchange.) As $\alpha$ rises, however, the holdup problem worsens, and eventually the firm or contract dominates the market. As to the choice between the latter two forms (which doesn't depend on $\alpha$ ), note that as $\theta$ increases, which means that the likelihood (and value) of performance is higher, the contract dominates the firm, as argued above. In contrast, when the likelihood of breach is high (which is true for low $\theta$ ), the firm dominates.

[Table 2 here]

The preceding analysis has identified those circumstances that tend to favor (or disfavor) the various organizational forms based on the incentives they create for performance and upfront investments. We can gain further insight regarding this choice by explicitly introducing the type and frequency of transaction costs associated with each form, which to this point we have ignored.

\section{The Impact of Transaction Costs}

Consider first the type of transaction costs associated with each form. Under the market, these will chiefly consist of the cost of negotiating the price and any other terms necessary to complete the transaction (e.g., the timing of payment and delivery). Let this cost be denoted $s$, which must be incurred each time the transaction occurs. In contrast, under a long-term contract, the parties need to agree up front to the price the ice company will pay in any transaction over a fixed time interval, thus eliminating the need to negotiate a new price with each transaction. Let this one-time cost be $N$. If the ice company chooses not to perform at this price due to the realized cost of performance, however, the parties will have go to court and incur litigation costs 
of $l$ per breach. Finally, if the two firms merge to form a single firm, this involves an up-front cost of integration, denoted $G$, which includes both the costs of organizing and of negotiating a wage contract (as described above) with workers. In comparing these various costs, it seems plausible to assume (i) $G>N$ (i.e., the fixed cost of integrating is larger than the fixed cost of negotiating a long-term contract), and (ii) $l>s$ (i.e., the cost of litigating is larger than the cost of negotiating a one-time transaction).

Perhaps more important than the relative magnitudes, however, is the frequency with which each cost is expected to be incurred under the various arrangements. Under the market arrangement, the cost $s$ must be incurred each time a transaction is completed. Let $n \geq 1$ be the (fixed) number of times the two firms expect to transact over a fixed time interval. For each "potential" transaction, the probability that the firms successfully transact is equal to the probability that the realized cost of performance is less than the value of performance, or the probability that $C \leq V(x)-s$, given $x$. Thus, the presence of transaction costs reduces the range of performance for each potential transaction compared to the above model. ${ }^{15}$ However, assuming that the parties incur an equal share of the negotiation cost (i.e., each incurs a cost $s / 2$ ), the price continues to be given by (4). Total expected transaction costs for the $n$ transactions are therefore given by

$$
T_{M}=F\left(V\left(x_{M}\right)-s\right) n s
$$

Under the long-term contract, the parties incur the one-time cost $N$ up-front, and then expect to incur litigation costs of $l$ each time the ice company breaches a potential transaction.

\footnotetext{
${ }^{15}$ It also lowers the optimal level of investment compared to that implied by (6) because the brewery's expected marginal benefit of investment is reduced. In particular, $x_{M}$ now solves $F(V(x)-s)(1-\alpha) V^{\prime}(x)-1=0$.
} 
Assuming that each side bears one-half of $l$, the ice company will perform if $R-C \geq-D-l / 2$, or if $C \leq V(x)+l / 2 .^{16}$ Expected transaction costs in this case are given by

$$
T_{C}=N+\left[1-F\left(V\left(x_{C}\right)\right)\right] n l .
$$

Finally, under the firm, only the up-front cost of integration is incurred. Thus, $T_{F}=G$.

[Figure 2 here]

Figure 2 graphs the total transaction costs under each organizational form as a function of $n$, the frequency of the interaction, where $n_{1}$ is determined by $T_{M}=T_{C}$, and $n_{2}$ is determined by $T_{C}=T_{F} \cdot{ }^{17}$ Generally, transaction costs are minimized under the market when the frequency of interaction is low $\left(n<n_{1}\right)$, under the contract when it is moderate $\left(n_{1}<n<\mathrm{n}_{2}\right)$, and under the firm when it is high $\left(n>n_{2}\right)$, all else equal. In addition, the market will become more attractive as the cost of negotiating a spot price and the probability of performance fall, while the contract will become more attractive as litigation costs and the probability of breach fall.

\section{Conclusion}

The optimal organizational form between two potential trading partners is the one that achieves the largest expected gains from trade. Alternatively stated, it is the form that minimizes the sum of transaction costs plus the cost associated with inefficient incentives for transaction-specific investments and performance. The contribution of this paper has been to examine markets, firms, and the law as alternative institutional arrangements for organizing transactions in the presence of these imperfections. This exercise represents the logical

\footnotetext{
${ }^{16}$ Thus, it performs too often compared to the above model. I assume that the court does not adjust the damage remedy to account for the distorting effect of litigation costs. It thus continues to set $D=V(x)-R$. I also assume that $V(x)-R>I / 2$ so that the brewery finds it worthwhile to sue for damages in the event of breach. The brewery's choice of $x$ is also affected by $l$; in particular, it invests at a higher level than is implied by (10) in order to reduce the probability of breach. In particular, $x_{C}$ now solves $V^{\prime}(x)[1+f(V+l / 2)(l / 2)]-1=0$.

${ }^{17}$ Thus, $n_{1}=N /\left\{F\left(V\left(x_{M}-s\right)\right) s-\left[1-F\left(V\left(x_{C}\right)\right)\right] l\right\}$ and $\left.n_{2}=(G-N) / 1-F\left(V\left(x_{C}\right)\right)\right] l$. In drawing the graph, I assume that $n_{2}>n_{1}$ so that each form is cost-minimizing over some range of $n$.
} 
extension of Coase's seminal contributions to industrial organization on one hand, reflected by his examination of the market-firm boundary, and to law and economics on the other, reflected by his examination of the market-law boundary. The result is a unified approach to organizational form that reveals the relative advantages and disadvantages, within a fairly simple economic setting, of market exchange, court ordering (contracts), and internal governance (agency). 


\section{References}

Baron, S. (1962) Brewed in America: A History of Beer and Ale in the United States, Boston: Little, Brown and Co.

Bolton, P. and M. Dewatripont (2005) Contract Theory, Cambridge, MA: MIT Press,

Calabresi, G. and A. D. Melamed (1972) "Property Rules, Liability Rules, and Inalienability: One View of the Cathedral," Harvard Law Review 85: 1089-1128.

Coase, R. (1960) “The Problem of Social Cost,” Journal of Law and Economics 3: 1-44. (1937) “The Nature of the Firm,” Economica 4: 386-405.

Edlin, A. and S. Reichelstein (1996) "Holdups, Standard Breach Remedies, and Optimal Investment," American Economics Review 86: 478-501.

Goldberg, V. (1976) "Regulation and Administered Contracts," Bell Journal of Economics 7: 426-448.

(1985) "Relational Exchange, Contract Law, and the Boomer Problem," Journal of Institutional Economics 144: 100-116.

Grossman, S. and O. Hart (1986) "The Costs and Benefits of Ownership: A Theory of Vertical and Lateral Integration,” Journal of Political Economy 94: 691-719.

Hart, O. (2011) “Thinking About the Firm: A Review of Daniel Spulber's The Theory of the Firm," Journal of Economic Literature 49: 101-113.

Hart, O. and J. Moore (1990) "Property Rights and the Nature of the Firm," Journal of Political Economy 98: 1119-1158.

(1988) "Incomplete Contracts and Renegotiation,” Econometrica 56: 755-785.

Klein, B., R. Crawford, and A. Alchian (1978) "Vertical Integration, Appropriable Rents, and the Competitive Contracting Process," Journal of Law and Economics 21: 297-326.

Miceli, T. (2002) “'Over a Barrel': Contract Modification, Reliance, and Bankruptcy," International Review of Law and Economics 22: 41-51.

Osborne, M. and A. Rubinstein (1990) Bargaining and Markets, San Diego: Academic Press.

Segal, I. (1999) "Complexity and Renegotiation: A Foundation for Incomplete Contracts," Review of Economic Studies 66: 57-82.

Shavell, S. (2004) Foundations of Economic Analysis of Law, Cambridge, MA: Belknap Press. 
White, M. (1988) "Contract Breach and Contract Discharge Due to Impossibility: A Unified Theory," Journal of Legal Studies 17: 353-376.

Williamson, O. (1987) “Transaction Cost Economics,” pp. 135-182, in R. Schmalensee and R. Willig, eds., Handbook of Industrial Organization, Amsterdam: North-Holland.

(1979) "Transaction Cost Economics: The Governance of Contractual Relations," Journal of Law and Economics 22: 233-161.

(1975) Markets and Hierarchies: Analysis and Antitrust Implications, New York: Free Press. 
Table 1. Outcomes under the various organizational forms.

\begin{tabular}{lll}
\hline Organizational form & Performance decision & Investment decision \\
Market & Efficient & Under-invest \\
Contract & Efficient & Over-invest \\
Firm & Under-perform & Efficient \\
\hline
\end{tabular}


Table 2. Optimal organizational form.

\begin{tabular}{ccccccccccc}
\multicolumn{10}{c}{$\theta=$} \\
\cline { 2 - 6 } & 2.5 & 2.6 & 2.7 & 2.8 & 2.9 & 3.0 & 3.1 & 3.2 \\
\hline 0 & $\mathrm{M}$ & $\mathrm{M}$ & $\mathrm{M}$ & $\mathrm{M}$ & $\mathrm{M}$ & $\mathrm{M}$ & $\mathrm{M}$ & $\mathrm{M}$ \\
.25 & $\mathrm{M}$ & $\mathrm{M}$ & $\mathrm{M}$ & $\mathrm{M}$ & $\mathrm{M}$ & $\mathrm{M}$ & $\mathrm{M}$ & $-\overline{\mathrm{C}}$ \\
.33 & $\mathrm{M}$ & $\mathrm{M}$ & $\mathrm{M}$ & $\mathrm{M}$ & $\mathrm{M}$ & $\mathrm{M}$ & $\mathrm{C}$ & $\mathrm{C}$ \\
.50 & $\mathrm{M}$ & $\mathrm{M}$ & $\mathrm{M}$ & $\mathrm{M}$ & $\mathrm{M}$ & $\mathrm{C}$ & $\mathrm{C}$ & $\mathrm{C}$ \\
.67 & $\mathrm{~F}$ & $\mathrm{~F}$ & $\mathrm{~F}$ & $\mathrm{~F}$ & $\mathrm{C}$ & $\mathrm{C}$ & $\mathrm{C}$ & $\mathrm{C}$ \\
.75 & $\mathrm{~F}$ & $\mathrm{~F}$ & $\mathrm{~F}$ & $\mathrm{~F}$ & $\mathrm{C}$ & $\mathrm{C}$ & $\mathrm{C}$ & $\mathrm{C}$ \\
1.0 & $\mathrm{~F}$ & $\mathrm{~F}$ & $\mathrm{~F}$ & $\mathrm{~F}$ & $\mathrm{C}$ & $\mathrm{C}$ & $\mathrm{C}$ & $\mathrm{C}$ \\
\hline
\end{tabular}

$\mathrm{M}=$ market, $\mathrm{C}=$ contract, $\mathrm{F}=$ firm 
Figure 1. Ranges for production and non-production under vertical integration.

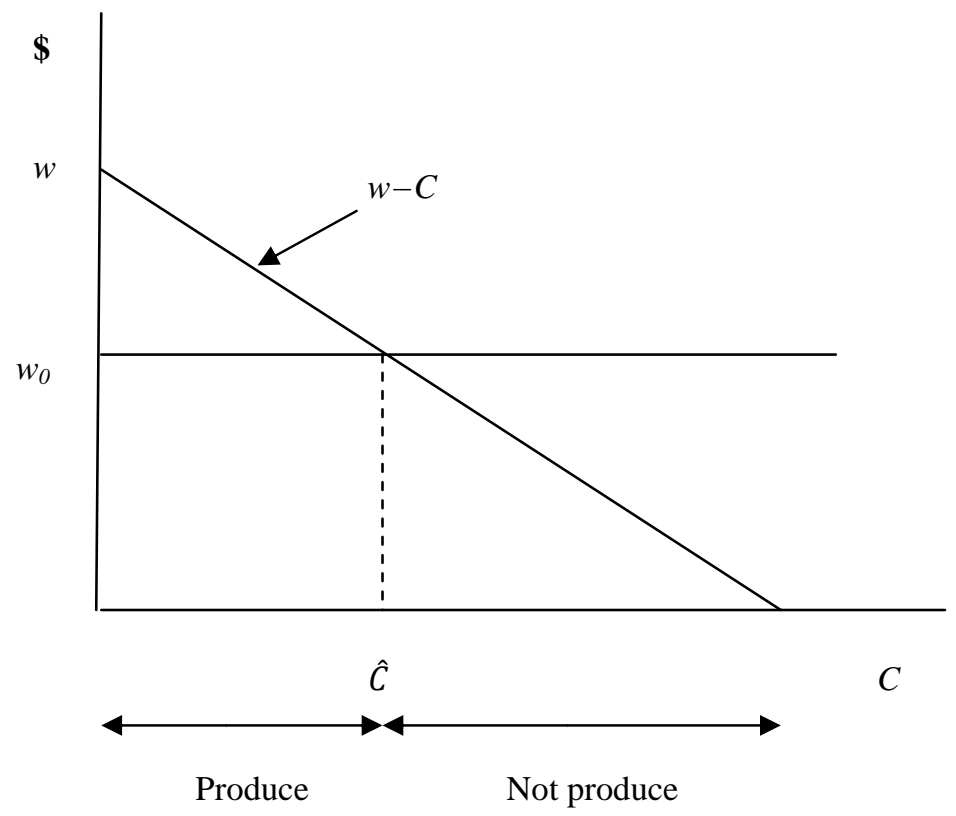


Figure 2. Transaction costs under the various organizational forms.

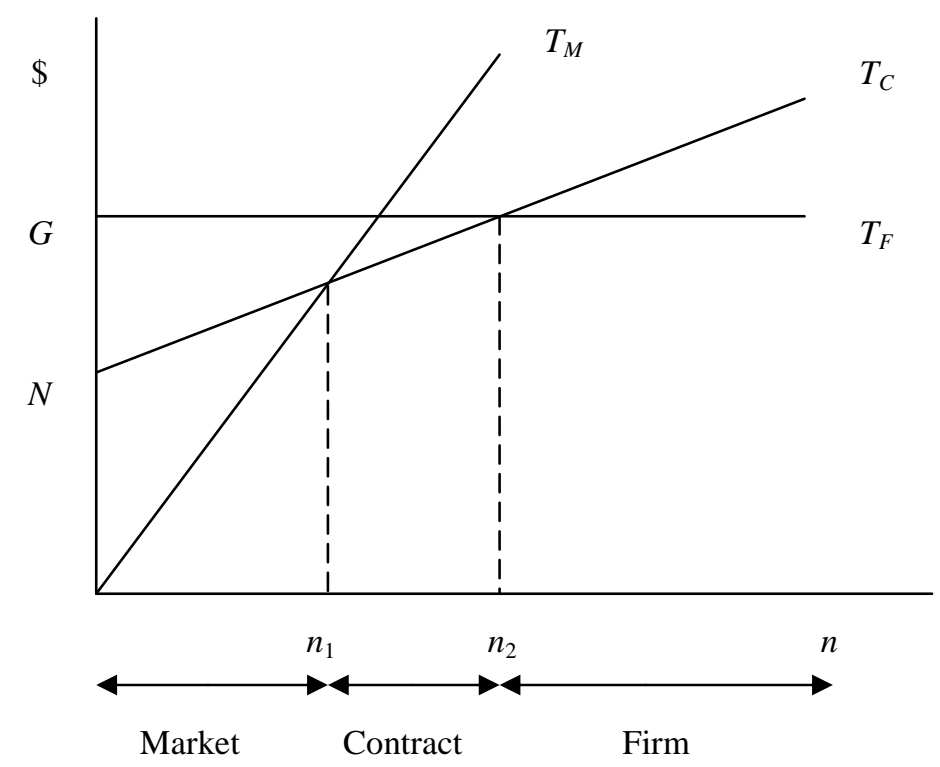

